Article

\title{
Studies on Anticonvulsant Effects of Novel Histamine H3R Antagonists in Electrically and Chemically Induced Seizures in Rats
}

\author{
Alaa Alachkar ${ }^{1}$, Dorota Łażewska ${ }^{2} \mathbb{D}$, Gniewomir Latacz ${ }^{2} \mathbb{D}$, Annika Frank $^{3} \mathbb{D}, \operatorname{Agata~Siwek~}^{4}$, \\ Annamaria Lubelska ${ }^{2}$, Ewelina Honkisz-Orzechowska ${ }^{2}$, Jadwiga Handzlik ${ }^{2}$, Holger Stark ${ }^{3}$ (D), \\ Katarzyna Kieć-Kononowicz ${ }^{2,+}$ and Bassem Sadek ${ }^{1, *,+}$ \\ 1 Department of Pharmacology \& Therapeutics, College of Medicine \& Health Sciences, United Arab Emirates \\ University, P.O. Box 17666, Al Ain, UAE; 201590025@uaeu.ac.ae \\ 2 Department of Technology and Biotechnology of Drugs, Faculty of Pharmacy, Jagiellonian University \\ Medical College, 9 Medyczna Street, 30-688 Kraków, Poland; dlazewska@cm-uj.krakow.pl (D.Ł.); \\ glatacz@cm-uj.krakow.pl (G.L.); annamaria@outlook.com (A.L.); ewelina.honkisz@uj.edu.pl (E.H.-O.); \\ jhandz@interia.pl (J.H.); mfkonono@cyf-kr.edu.pl (K.K.-K.) \\ 3 Institute of Pharmaceutical and Medicinal Chemistry, Heinrich Heine University Düsseldorf, \\ Universitaetsstr. 1, 40225 Düsseldorf, Germany; a.frank@hhu.de (A.F.); stark@hhu.de (H.S.) \\ 4 Department of Pharmacobiology, Faculty of Pharmacy, Jagiellonian University Medical College, 9 Medyczna \\ Street, 30-688 Kraków, Poland; agat.siwek@uj.edu.pl \\ * Correspondence: bassem.sadek@uaeu.ac.ae; Tel.: +971-3-7137-512, Fax: +971-3-7672-033 \\ + These authors have contributed equally to this work.
}

Received: 9 October 2018; Accepted: 26 October 2018; Published: 29 October 2018

\begin{abstract}
A newly developed series of non-imidazole histamine $\mathrm{H} 3$ receptor (H3R) antagonists (1-16) was evaluated in vivo for anticonvulsant effects in three different seizure models in Wistar rats. Among the novel H3R antagonists examined, H3R antagonist 4 shortened the duration of tonic hind limb extension (THLE) in a dose-dependent fashion in the maximal electroshock (MES)-induced seizure and offered full protection against pentylenetetrazole (PTZ)-induced generalized tonic-clonic seizure (GTCS), following acute systemic administration $(2.5,5,10$, and $15 \mathrm{mg} / \mathrm{kg}$, i.p.). However, only H3R antagonist 13, without appreciable protective effects in MES- and PTZ-induced seizure, fully protected animals in the strychnine (STR)-induced GTCS following acute systemic pretreatment $(10 \mathrm{mg} / \mathrm{kg}$, i.p.). Moreover, the protective effect observed with H3R antagonist 4 in MES-induced seizure was completely abolished when animals were co-administered with the H3R agonist $(R)$ - $\alpha$-methylhistamine (RAMH, $10 \mathrm{mg} / \mathrm{kg}$, i.p.). However, RAMH failed to abolish the full protection provided by the H3R antagonist 4 in PTZ-induced seizure and H3R antagonist 13 in STR-induced seizure. Furthermore, in vitro antiproliferative effects or possible metabolic interactions could not be observed for compound 4. Additionally, the predictive in silico, as well as in vitro, metabolic stability for the most promising H3R antagonist 4 was assessed. The obtained results show prospective effects of non-imidazole H3R antagonists as innovative antiepileptic drugs (AEDs) for potential single use against epilepsy.
\end{abstract}

Keywords: histamine H3 receptors; antagonists; anticonvulsant; maximal electroshock; pentylenetetrazole; strychnine; antiproliferative action; metabolic stability

\section{Introduction}

Epilepsy is considered as a brain disease characterized by repeated seizures due to different complex causes including idiopathic (ion channel or protein defects), symptomatic stroke, head injury 
(tumors in the brain or central infectious diseases), metabolic disorders (e.g., imbalance of several electrolytes, uremia, and hyperglycemia), or genetic mutation of DNA sequences in genes responsible for encoding various ion channels or neurotransmitter receptors [1,2]. In addition, many patients diagnosed with epilepsy also show cognitive comorbid features, for example, deficiency in intellectual ability; impaired learning and memory; and behavioral neuropsychiatric disorders, such as depression, aggression, or problems in social relationships that intensify the costs for their healthcare [3]. Clinically obtainable antiepileptic drugs (AEDs) still have a large number of non-responders with the clinical drawback that around $30 \%$ of epileptic patients do not respond to current therapies [4,5]. More than fifteen new AEDs, including lamotrigine, levetiracetam, retigabine, and perampanel, were approved during the last twenty-five years [6]. However, numerous AEDs cause several unwanted adverse effects, with the most common ones being behavioral and cognitive deficiencies, weight gain, coordination problems, dizziness, and gait disturbance [6]. As long life drug treatment is indispensable, the search for new and more effective AEDs with improved safety profiles is an imperative therapeutic goal [5]. Therefore, there is still a high therapeutic need for new medical entities.

Preclinical and clinical studies indicated that several brain monoamines such as serotonin, dopamine, noradrenaline, histamine, or melatonin play a significant role in seizure activity $[7,8]$. Previous studies have investigated in the brain histamine's role in seizure pathophysiology $[9,10]$. Accordingly, histamine itself is considered as an endogenous anticonvulsant $[9,11]$, while histamine H1 receptor (H1R) antagonists were found to prompt or promote seizures [12,13]. Furthermore, preclinical experiments in several rodents revealed that inhibition of $N$-methyltransferase, the histamine metabolizing enzyme in the central nervous system (CNS), using metoprine elevated the levels of brain histamine and, therefore, reduced seizure susceptibility [14-17]. On the other hand, $\alpha$-fluoromethylhistidine ( $\alpha$-FMH, the histamine synthesizing enzyme in the CNS) escalated seizure activity in experimental animals as a result of inhibition of histidine decarboxylase (HDC), which minimized the biosynthesis of brain histamine [18].

Histamine acts by four distinct histamine receptor subtypes (H1R-H4R), which belong to class A of the G-protein coupled receptor family [19]. H1R and H2R are largely found in the CNS and periphery, H3Rs are abundant in the brain, while H4Rs are chiefly expressed in mast cells and leukocytes [20]. Activation of H1R and H2R stimulates slow excitatory postsynaptic potential, while H3Rs is coupled to $G_{i} / G_{0}$-proteins, which regulate the biosynthesis and release of brain histamine by acting as auto-receptors $[19,21,22]$. Moreover, H3Rs operating as hetero-receptors can also modulate the release of various other brain neurotransmitters in different brain regions, for example, acetylcholine, glutamate, gamma-aminobutyric acid (GABA), norepinephrine, serotonin, and dopamine [23].

Previous experimental observations from our research [24-30] and that of other research groups [18,31-34] signified the anticonvulsant activity of several histamine H3R antagonists, which could be connected to their antagonistic effects on histamine H3Rs. In different rodent models of seizure, both the imidazole-based H3R antagonist thioperamide $[32,35,36]$ and non-imidazole-based H3R antagonists [26-29] reduced seizures or displayed full protective effects in the maximal electroshock (MES)- and pentylenetetrazole (PTZ)-induced seizure models. Pitolisant (PIT), which is the first H3R antagonist to reach the market (Wakix ${ }^{\circledR}$; Bioprojet Pharma-as an orphan drug for the treatment of narcolepsy [37]), also presented effectiveness in different animal models of epilepsy $[25,33,38]$, which could not be confirmed so far in clinical trials [34] (Table 1).

Based on the aforementioned preclinical and clinical results, the current study examined the anticonvulsant effects of newly developed $\mathrm{N}$-alkyl-substituted (homo)piperidine ether derivatives (1-16) (Table 1). These novel H3R antagonists (1-16) were developed as structural modifications of PIT and comprise different cycloalkylamine functionalities in the basic part of target ligands, different alkyl chain lengths (five or six methylene groups), as well as variable positions of methyl at the basic piperidine ring $\left(3-\mathrm{CH}_{3}\right.$ or $\left.4-\mathrm{CH}_{3}\right)$ (Table 1). First, their in vitro affinities on human histamine H3Rs ( $h \mathrm{H} 3 \mathrm{Rs}$ ) were evaluated. Second, their anticonvulsant effects were examined in the MES-, PTZ-, and strychnine (STR)-induced seizures in male adult rats. The latter 
in vivo seizure test models were selected based on earlier preclinical observations, in which the anticonvulsant efficacy of numerous imidazole as well as non-imidazole H3R antagonists was established [39-41]. Third, the ability of the CNS penetrant H3R agonist $(R)-\alpha$-methylhistamine (RAMH) to counteract the protection provided by the most promising H3R antagonists was considered. Fourth, the in vitro selectivity profile towards HRs subtypes for compounds with the most promising anticonvulsant effects was evaluated on human HRs expressed in different cell lines. Fifth, the absorption-distribution-metabolism-excretion-Toxicology (ADME-Tox) profile of the H3R antagonist with the most promising anticonvulsant efficacy was further assessed for antiproliferative activity, for metabolic stability, and for the potential of drug-drug interaction.

\section{Material and Methods}

\subsection{In Vitro Pharmacology}

\subsubsection{Human Histamine H3 Receptor (hH3R) Binding Affinity for Tested Compounds 1-16}

As described previously $[28,42,43]$, the affinity for the human histamine H3R was tested utilizing radioligand displacement assays with $\left[{ }^{3} \mathrm{H}\right] N^{\alpha}$-methylhistamine at membrane preparations from human embryonic kidney (HEK)-293 cells, stably expressing the receptor. Assays ran in triplicates with seven concentrations of the test compounds 1-16 (Table 1). The analysis of data was conducted by the software GraphPad Prism 7 (San Diego, CA, USA), using the "one-site competition" equation. $K_{\mathrm{i}}$ values were calculated from the 50 percent of inhibitory concentration $\left(\mathrm{IC}_{50}\right)$ values according to the Cheng-Prusoff equation [44] (Table 1).

Table 1. In vitro human histamine $\mathrm{H} 3$ receptor (hH3R) affinities of ligands 1-16.

Ligand In Vitro Affinity $\mathbf{K}_{\mathbf{i}}\left(\mathbf{h H}_{3} \mathbf{R}^{\mathrm{a}}\right.$ in $\mathbf{n M}$ [CI]


Table 1. Cont.

\begin{tabular}{|c|c|c|}
\hline Ligand & Structure & In Vitro Affinity $K_{\mathrm{i}}\left(\mathrm{hH}_{3} \mathrm{R}\right)^{\mathrm{a}}$ in $\mathrm{nM}[\mathrm{CI}]$ \\
\hline 9 & & $\begin{array}{c}110.2 \\
{[61.8 ; 196.4]}\end{array}$ \\
\hline 10 & & $\begin{array}{c}69.5 \\
{[44.4 ; 108.8]}\end{array}$ \\
\hline 11 & & $\begin{array}{c}115.2 \\
{[78.4 ; 169.5]}\end{array}$ \\
\hline 12 & & $\begin{array}{c}83.6 \\
{[65.8 ; 106.4]}\end{array}$ \\
\hline 13 & & $\begin{array}{c}137.2 \\
{[60.0 ; 313.9]}\end{array}$ \\
\hline 14 & & $\begin{array}{c}36.2 \\
{[10.0 ; 130.3]}\end{array}$ \\
\hline 15 & & $\begin{array}{c}40.2 \\
{[13.5 ; 119.4]}\end{array}$ \\
\hline 16 & & $\begin{array}{c}38.5 \\
{[10.5 ; 141.6]}\end{array}$ \\
\hline Pitolisant (PIT) & & $11.69^{c}$ \\
\hline
\end{tabular}

${ }^{a}\left[{ }^{3} \mathrm{H}\right] N^{\alpha}$-Methylhistamine binding assay performed with cell membrane preparations of human embryonic kidney (HEK) cells stably expressing the human histamine H3R. CI—confidence interval; ${ }^{b}$ data from Łażewska et al., 2018;

${ }^{c}$ data from the literature [45].

\subsubsection{Human Histamine H1 Receptor (hH1R) Binding Affinity for Selected Compounds $\mathbf{4}, \mathbf{7}$ and $\mathbf{1 3}$}

Radioligand binding was performed as previously described using membranes from CHO-K1 cells stably transfected with the human H1 receptor (PerkinElmer., Waltham, MA, USA) [30,42]. Data were fitted to a one-site curve-fitting equation with Prism 6 (GraphPad Software, city, state, country) and $K_{\mathrm{i}}$ values were estimated from the Cheng-Prusoff equation [44].

\subsubsection{Human Histamine H4 Receptor (hH4R) Binding Affinity for Selected Compounds $\mathbf{4}, \mathbf{7}$ and $\mathbf{1 3}$}

H4R radioligand displacement assays were performed with Sf9 cell membrane preparations, expressing the $\mathrm{hH} 4 \mathrm{R}$, as described previously $[28,42,43]$. Assays ran in triplicates with four appropriate concentrations of the test compound. Data were analyzed by GraphPad Prism 7, using the "one-site competition" equation.

\subsection{In Vivo Pharmacology}

\subsubsection{Animals}

Inbred male Wistar rats aged between six and eight weeks (body weight: 180-220 g, Central Animal Facility of the United Arab Emirates (UAE) University, Al Ain/Abu Dhabi, United Arab 
Emirates) were used. Animals were kept in an air-conditioned animal facility room with controlled temperature $\left(24 \pm 1{ }^{\circ} \mathrm{C}\right)$ and humidity $(55 \pm 15 \%)$ under a 12-h light/dark cycle. The animals were allowed free access to food and water. The experiments of the current study were carried out between 09:00 and 12:00, and all procedures were performed according to the guidelines of the European Communities Council Directive of 24 November 1986 (86/609/European Economic Community (EEC)) and were previously approved for epilepsy study by the College of Medicine and Health Sciences/United Arab Emirates University (Institutional Animal Ethics Committee, approval number; ERA_2017_5676).

\subsubsection{Drugs}

H3R agonist (R)- $\alpha$-methylhistamine (RAMH, $10 \mathrm{mg} / \mathrm{kg}$, i.p.), pentylenetetrazole (PTZ, $60 \mathrm{mg} / \mathrm{kg}$, i.p.), strychnine (STR, $3.5 \mathrm{mg} / \mathrm{kg}$, i.p.), phenytoin (PHT), and valproic acid (VPA, $300 \mathrm{mg} / \mathrm{kg}$, i.p) were purchased from Sigma-Aldrich (St Louis, MI, USA). H3R antagonists: (1) 3-methyl-1-(5-(naphthalen-2-yloxy)pentyl)piperidine hydrogen oxalate [45]; (2) 1-(5-(naphthalen-2-yloxy)pentyl)azepane hydrogen oxalate [45]; (3) 3-methyl-1-(6-(naphthalen-2-yloxy)hexyl)piperidine hydrogen oxalate [45]; (4) 1-(6-(naphthalen2-yloxy)hexyl)azepane hydrogen oxalate [45]. All other compounds are unpublished to best of our knowledge: (5) phenyl(4-(6-(piperidin-1-yl)hexyloxy)phenyl)methanone hydrogen oxalate; (6) (4-(6-(3-methylpiperidin-1-yl)hexyloxy)phenyl)(phenyl)methanone hydrogen oxalate; (7) (4-(6-(azepan-1-yl)hexyloxy)phenyl)(phenyl)methanone hydrogen oxalate; (8) phenyl(3-(6-(piperidin-1yl)hexyloxy)phenyl)methanone hydrogen oxalate (unpublished); (9) (3-(6-(3-methylpiperidin-1-yl) hexyloxy)phenyl)(phenyl)methanone hydrogen oxalate; (10) (3-(6-(azepan-1-yl)hexyloxy)phenyl) (phenyl)methanone hydrogen oxalate; (11) 1-(6-(4-fluorophenoxy)hexyl)piperidine hydrogen oxalate; (12) 1-(6-(4-fluorophenoxy)hexyl)-3-methylpiperidine hydrogen oxalate; 1-(6-(4-fluorophenoxy)hexyl)azepane hydrogen oxalate; (14) phenyl(4-(5-(piperidin-1-yl)pentyloxy)phenyl) methanone hydrogen oxalate; (15) (4-(5-(3-methylpiperidin-1-yl)pentyloxy)phenyl)(phenyl)methanone hydrogen oxalate; and (16) (4-(5-(azepan-1-yl)pentyloxy)phenyl)(phenyl)methanone hydrogen oxalate. These synthesized by us in the Department of Technology and Biotechnology of Drugs (Kraków, Poland) (Table 1) according to methods described previously [24,45]. For the in vivo anticonvulsant screening, test compounds 1-16, PHT, VPA, and RAMH were suspended in $1 \%$ aqueous solution of Tween 80 and administered intraperitoneally (i.p.) at a volume of $1 \mathrm{~mL} / \mathrm{kg} \mathrm{30-45} \mathrm{min} \mathrm{before} \mathrm{the} \mathrm{test.}$ Control animals (negative control) were given an appropriate amount of vehicle ( $1 \%$ aqueous solution of Tween 80; i.p.) 30-45 min before the test. Doses of all test compounds were expressed in terms of the free base. For each test compound, a group of six to seven animals was used for the anticonvulsant study (Table 1).

\subsubsection{Maximal Electroshock (MES)-Induced Seizure}

As previously described $[30,46]$, the seizures were induced in rats with a $50 \mathrm{~Hz}$ alternating current of $120 \mathrm{~mA}$ intensity. The current was applied through ear electrodes for $1 \mathrm{~s}$. Protection against the spread of MES-induced seizure was defined as the abolition of the tonic hind limb extension (THLE) component of the seizure $[25,29,47]$. For the first screening of protective effects of test compounds 1-16 in the MES-induced seizure model, the animals were divided into eighteen groups of seven rats $(n=7)$ as follows; group (1) control group injected with vehicle (SAL), group (2) positive control group in which rats were injected with PHT at a dose of $10 \mathrm{mg} / \mathrm{kg}$ (this being the minimal dose of PHT that protected animals against the spread of MES-induced seizures without mortality), and groups (3)-(18) animals in the experimental groups were administered H3R antagonists 1-16 at a dose of $10 \mathrm{mg} / \mathrm{kg}$. In another MES experiment in three separate groups of six rats $(n=6)$, H3R antagonist 4 with the most promising protection in MES model was administered at doses of 2.5, 5 , or $15 \mathrm{mg} / \mathrm{kg}$, i.p. 30-45 min before the MES challenge. In an additional abrogative experiment, the most effective dose of H3R antagonist 4 was designated for further analysis in which a separate group of six rats 
$(n=6)$ was co-injected with the selected dose of H3R antagonist 4 (30-45 min prior to MES test) with RAMH (10 mg/kg, i.p., 15-20 min before MES challenge) (Figure 1, Table 2).

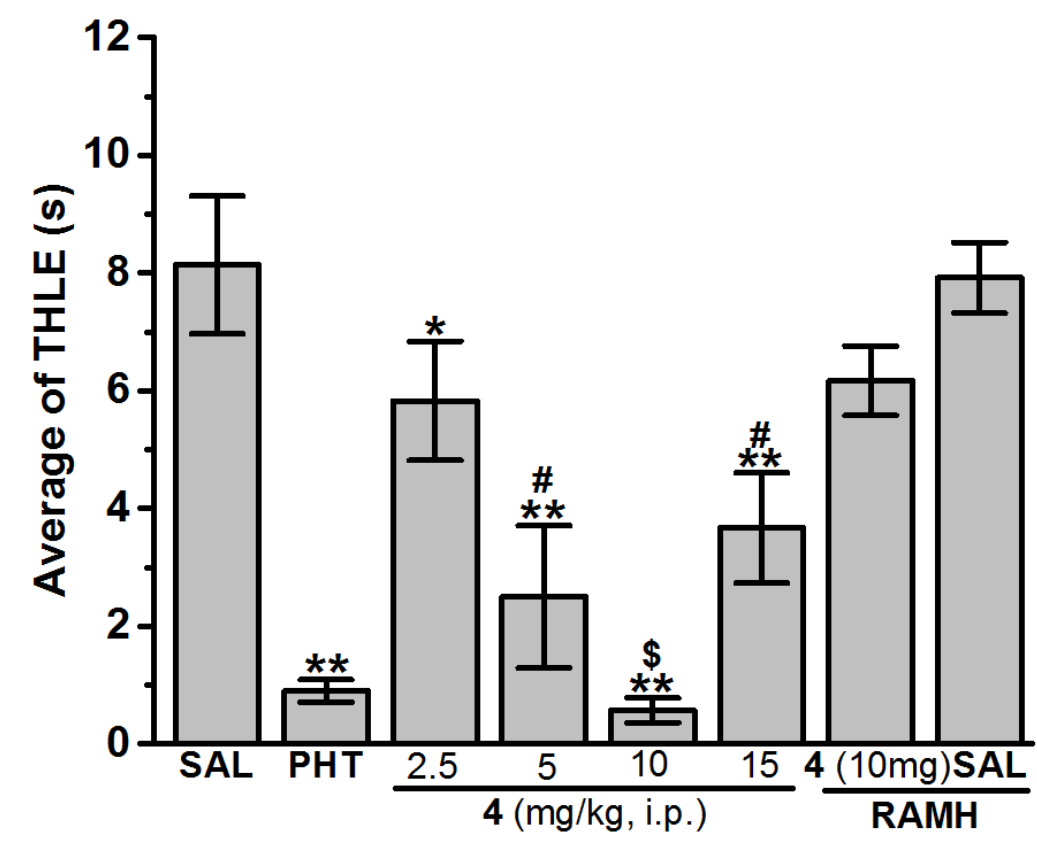

Figure 1. Dose-dependent protective effect of histamine H3 receptor (H3R) antagonist 4 and effect of $(R)-\alpha$-methylhistamine (RAMH) pretreatment on the H3R antagonist 4 provided protection against maximal electroshock (MES)-induced convulsions. The figure shows the protection provided by standard antiepileptic drug (AED) phenytoin (PHT, $10 \mathrm{mg} / \mathrm{kg}$, i.p.) and test compound 4 (2.5, 5, 10, and $15 \mathrm{mg} / \mathrm{kg}$, i.p.) on the duration of tonic hind limb extension (THLE) induced in the MES model in rats. Each value represents mean \pm standard error of mean (SEM) $(n=6-7) .{ }^{*} p<0.05$ vs. sal (saline)-treated group. ${ }^{* *} p<0.001$ vs. (saline)-treated group. ${ }^{\#} p<0.05$ vs. (2.5 mg)-treated group. ${ }^{\$} p<0.05$ vs. (5 mg or $15 \mathrm{mg})$-treated groups.

Table 2. Screening of in vivo anticonvulsant effects for H3R antagonists 1-16.

Ligand


Table 2. Cont.

\begin{tabular}{|c|c|c|c|c|}
\hline Ligand & Structure & MES $^{\text {a }-I n d u c e d ~ S e i z u r e ~}$ & PTZ $^{\mathrm{b}}$-Induced Seizure & STR ${ }^{\mathrm{C}}$-Induced Seizure \\
\hline 7 & & + & ++ & - \\
\hline 8 & & + & - & - \\
\hline 9 & & - & - & - \\
\hline 10 & & - & - & - \\
\hline 11 & & - & ++ & - \\
\hline 12 & & - & + & - \\
\hline 13 & & - & + & + \\
\hline 14 & & + & + & - \\
\hline 15 & & - & + & - \\
\hline 16 & & - & - & - \\
\hline
\end{tabular}

a $50-\mathrm{Hz}$ alternating current of $120 \mathrm{~mA}$ intensity applied through ear electrodes for a duration of $1 \mathrm{~s},{ }^{b} 60 \mathrm{mg} / \mathrm{kg},{ }^{\mathrm{c}}$ $3.5 \mathrm{mg} / \mathrm{kg}$. - , no protection (not significant from saline-treated group); + , moderate protective effect (tonic hind limb extension (THLE) duration in the range of $2-5 \mathrm{~s}$, seizure score in the range of $2-4$ ); ++ , high protective effect (THLE duration <1, seizure score 0). MES—-maximal electroshock; PTZ—pentylenetetrazole; STR — strychnine.

\subsubsection{Chemically-Induced Seizures}

In this study and according to previously used protocols, two chemical agents have been used to induce seizures, namely pentylenetetrazole (PTZ, $60 \mathrm{mg} / \mathrm{kg}$, i.p.) and strychnine (STR, $3.5 \mathrm{mg} / \mathrm{kg}$, i.p.) [27,47]. PTZ $60 \mathrm{mg} / \mathrm{kg}$ or STR $3.5 \mathrm{mg} / \mathrm{kg}$ were administered i.p. to all groups of seven rats $(n=7)$, that is, animals pretreated with vehicle or test compounds $\mathbf{1}-\mathbf{1 6}$. Vehicle, VPA ( $300 \mathrm{mg} / \mathrm{kg}$, i.p.), [26,47-49] or test compounds $\mathbf{1}-\mathbf{1 6}$ (10 $\mathrm{mg} / \mathbf{k g}$, i.p.) were systemically administered 30-45 min before PTZ (60 mg/kg, i.p.) or STR (3.5 mg/kg, i.p.) injection, and animals were directly observed for any signs of convulsion for a duration of $30 \mathrm{~min}$. The observed scores as well as percent protection against generalized tonic-clonic seizure (GTCS) were graded and scaled according to the Racine scale (stage 0 , no change in behavior; stage 1, stereotype mouthing, eye blinking, and/or mild facial clonus; stage 2, head nodding and / or severe facial clonus; stage 3, myoclonic jerk in forelimbs; stage 4, clonic convulsions in the forelimbs with rearing; stage 5, generalized colonic convulsions associated with loss of balance [50]) to evaluate the protection provided by the respective test compound against seizures. The animals were divided into eighteen groups of seven rats $(n=7)$ and treated as follows.

(1) Control group injected with vehicle + PTZ (SAL group), (2) positive control group in which rats were injected with VPA (300 mg/kg) + PTZ (VPA group), and animals in the test groups (3)-(18) 
were systemically administered with test compounds 1-16 $(10 \mathrm{mg} / \mathrm{kg})$, respectively. An additional PTZ experiment was conducted using three different groups of seven rats $(n=7)$, the H3R ligand with the most promising protection in PTZ model was administered at doses of 2.5, 5, or $15 \mathrm{mg} / \mathrm{kg}$, i.p. 30-45 min before the PTZ challenge. In an additional abrogative PTZ experiment, the most effective dose of H3R antagonist 4 was selected for further analysis, namely in a separate group of seven rats $(n=7)$, the selected dose of 4 was co-injected (30-45 min prior to PTZ test) together with RAMH (10 mg/kg, i.p., 15-20 min before PTZ challenge) (Figure 2, Table 2). The same experimental procedure was followed in the STR-induced seizure model applying the reference drug VPA, which was used at a dose of $300 \mathrm{mg} / \mathrm{kg}$, i.p. (Figure 3, Table 2).

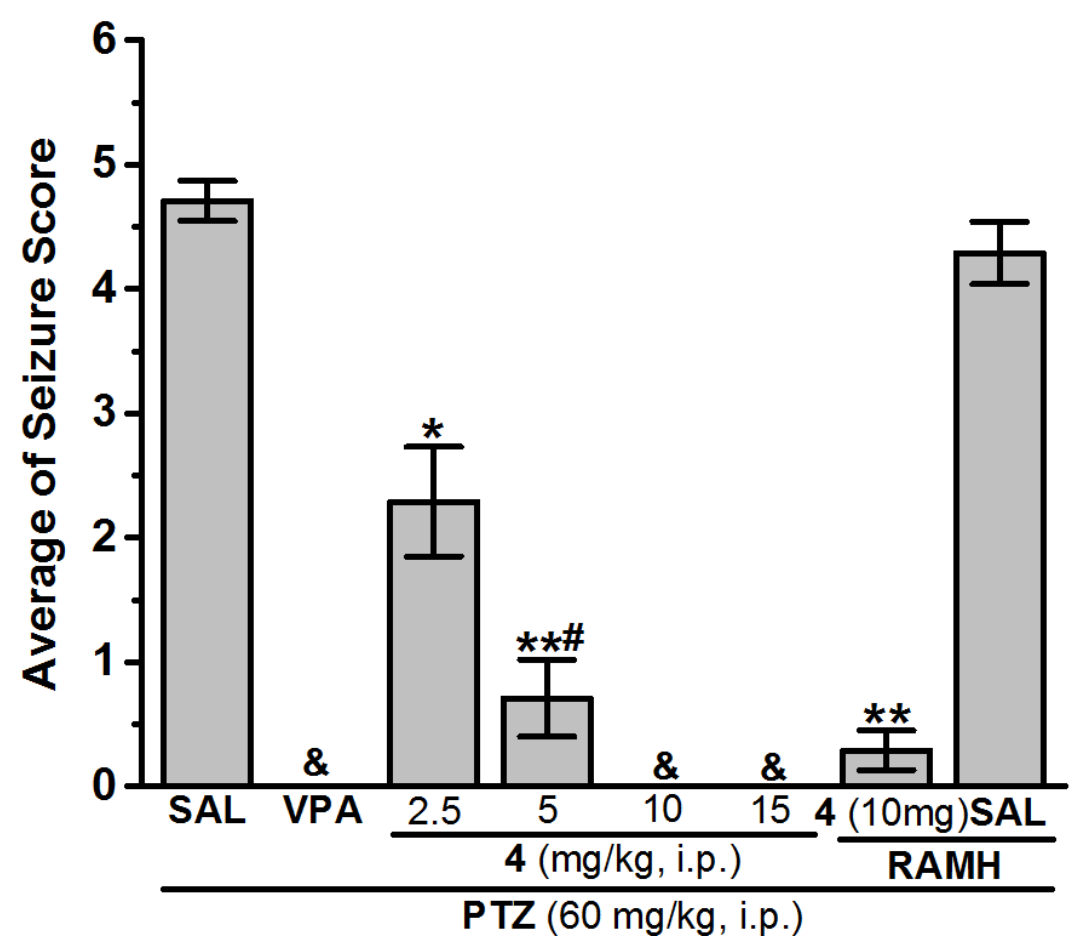

Figure 2. Anticonvulsant effect of $\mathrm{H} 3 \mathrm{R}$ antagonist 4 pretreatment on pentylenetetrazole (PTZ)-induced convulsion in rats. Valproic acid (VPA, $300 \mathrm{mg} / \mathrm{kg}$, i.p.) and test compound 4 (2.5, 5, 10, and $15 \mathrm{mg} / \mathrm{kg}$, i.p.) were injected 30-45 $\mathrm{min}$ before PTZ $(60 \mathrm{mg} / \mathrm{kg}$, i.p.) treatments. Values are represented as the mean $\pm \operatorname{SEM}(n=7) .{ }^{*} p<0.05$ vs. (saline)-treated group. ${ }^{* *} p<0.001$ vs. (saline)-treated group. ${ }^{\#} p<0.05$ vs. (2.5 mg)-treated group. \& Full protection.

\subsubsection{Statistical Analysis}

For statistical comparisons, the software package SPSS 25.0 (IBM Middle East, Dubai, UAE) was used. All data are expressed as the means \pm standard error of mean (SEM). $K_{i}$ values at the H3R are given as means with the $95 \%$ confidence interval. Following normal distribution assessment, the anticonvulsant effects observed for H3R antagonists 1-16 in MES-, PTZ-, and STR-induced convulsion models were analyzed using one-way analysis of variance, followed by the Bonferroni post hoc test for multiple comparisons. The criterion for statistical significance was set at $p<0.05$. 


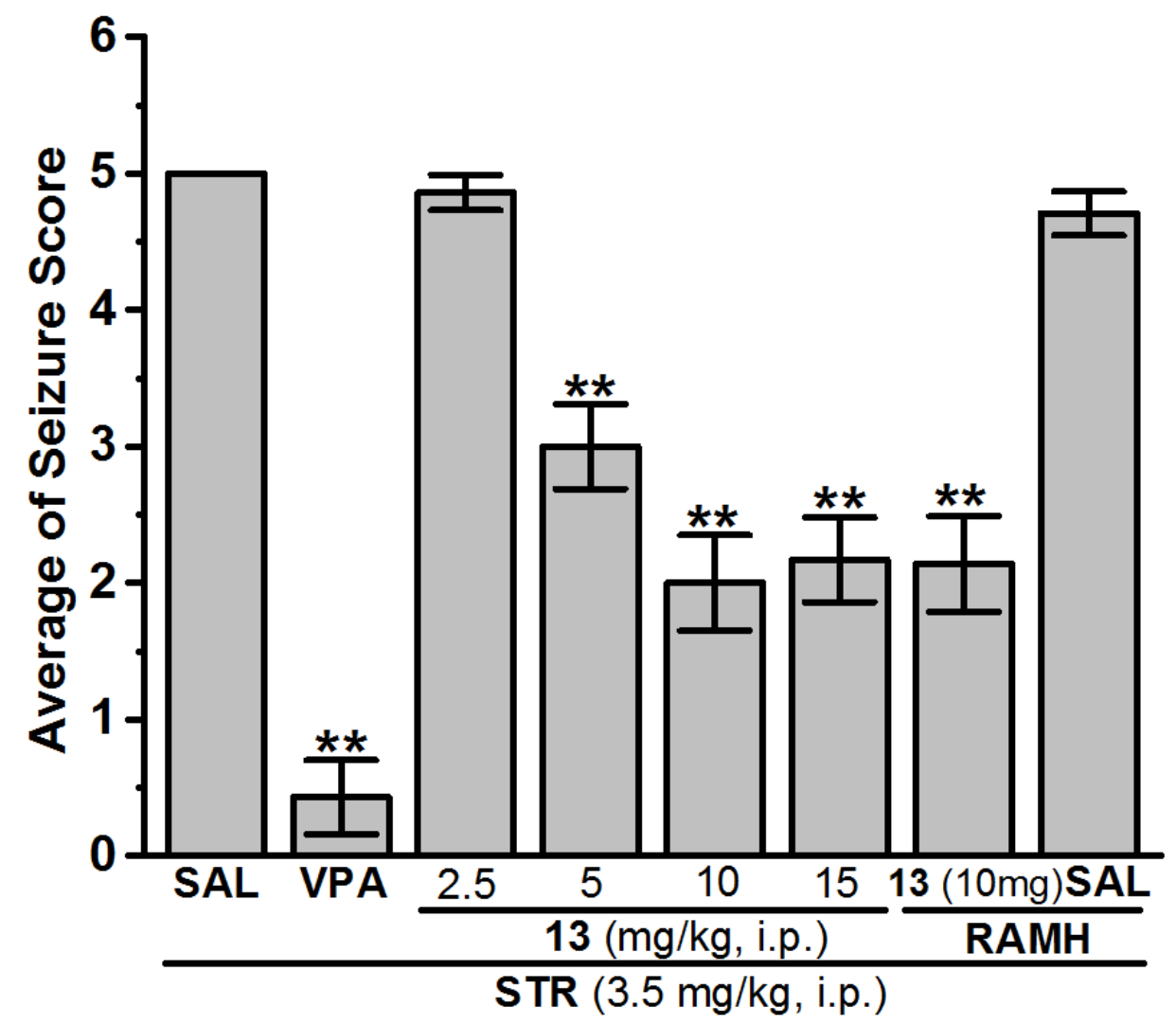

Figure 3. Anticonvulsant effect of $\mathrm{H} 3 \mathrm{R}$ antagonist 13 pretreatment on strychnine (STR)-induced seizure in rats. Valproic acid (VPA, $300 \mathrm{mg} / \mathrm{kg}$, i.p.) and test compound $\mathbf{1 3}(2.5,5,10$, and $15 \mathrm{mg} / \mathrm{kg}$, i.p.) were injected 30-45 min before STR (3.5 mg/ kg, i.p.) treatments. Values are represented as the mean \pm SEM $(n=7) .{ }^{* *} p<0.001$ vs. (saline)-treated group.

\subsection{ADME-Tox Properties}

\subsubsection{Antiproliferative Activity}

Human embryonic kidney (HEK)-293 cell line (ATCC CRL-1573) was kindly donated by Prof. Dr. Christa Müller (Pharmaceutical Institute, Pharmaceutical Chemistry I, University of Bonn). Hepatoma HepG2 (ATCC HB-8065) cell line was kindly donated by the Department of Pharmacological Screening, Jagiellonian University Medical College. The cell cultures' growth conditions in presence of H3R antagonist 4 were applied as described before [46,51]. The cells' viability was assessed after $72 \mathrm{~h}$ of incubation with H3R antagonist and the following references: doxorubicin (Sigma-Aldrich) and carbonyl cyanide 3-chlorophenylhydrazone (CCCP) (Sigma-Aldrich). CellTiter $96^{\circledR}$ AQueous non-radioactive cell proliferation assay (MTS) was purchased from Promega ${ }^{\circledR}$ and added to each well in the volume of $20 \mu \mathrm{L}$. The cells were then incubated for 2-5 h. The microplate reader EnSpire (PerkinElmer Ltd., Waltham, MA, USA) was used to measure the absorbance at $490 \mathrm{~nm}$.

\subsubsection{Prediction of In Silico Metabolism}

The in silico prediction for sites of metabolism of H3R antagonist 4 was performed by MetaSite 5.1.1 provided by Molecular Discovery Ltd. (Borehamwood, Hertfordshire, UK). The most probable sites of metabolism were predicted during this study by the liver computational model [52] (Figure 5).

\subsubsection{Metabolic Stability}

Rat liver microsomes (RLMs) purchased form Sigma-Aldrich (St. Louis, MO, USA) were used for in vitro determination of compound 4's metabolic stability. The NADPH regeneration system 
was purchased from Promega (Madison, WI, USA). All experiments were performed as described before $[26,45,46]$. The reaction mixture was preincubated at $37^{\circ} \mathrm{C}$ for $5 \mathrm{~min}$, and then the reaction was started by adding $50 \mu \mathrm{L}$ of NADPH regeneration system. The reaction was ended after $120 \mathrm{~min}$ by the addition of cold methanol $(200 \mu \mathrm{L})$. The mixture was then centrifuged at 14,000 rpm for $15 \mathrm{~min}$ and the ultra-performance liquid chromatography-mass spectrometry (UPLC/MS) analysis of the supernatant was conducted. Ion fragment analyses were also performed for metabolic pathways' determination.

\subsubsection{Metabolic Interactions}

The metabolic interactions of H3R antagonist 4 were determined by the luminescent P450-Glo ${ }^{\mathrm{TM}}$ $3 \mathrm{~A} 4$ and 2D6 assays purchased from Promega ${ }^{\circledR}$. All enzymatic reactions were performed according to the manufacturer protocols and as previously described [26]. The references ketoconazole (KE, CYP3A4 inhibitor) and quinidine (QD, CYP2D6 inhibitor) were obtained from Sigma-Aldrich. The luminescence was measured with a microplate reader EnSpire (PerkinElmer). The final concentration of H3R antagonist 4 was in the range of $0.1-25 \mu \mathrm{M}$, whereas reference inhibitory effects ranged from $0.01 \mu \mathrm{M}$ to $10 \mu \mathrm{M}$. The $\mathrm{IC}_{50}$ values' calculations were performed by GraphPad Prism ${ }^{\mathrm{TM}}$ software (version 5.01, San Diego, CA, USA).

\section{Results}

\subsection{Pharmacology}

\subsubsection{In Vitro Affinities at hH1Rs, hH3Rs, and hH4Rs}

The novel ligands 1-16 were tested for their H3R affinity by $\left[{ }^{3} \mathrm{H}\right] N^{\alpha}$-methylhistamine displacement assays on membrane preparations of HEK-293 cells, stably expressing the hH3R (Table 1). Following assessment of in vivo anticonvulsant effects in MES-, PTZ-, and STR-induced seizure models for H3R antagonists 1-16, only selected H3R antagonists (4, 7, and 13), with the most promising in vivo anticonvulsant effects, were further evaluated for their affinity at human histamine H1 (hH1R) and H4 (hH4R) receptors. The results show that test compounds 1-16 had an H3R affinity of 40-140 nM compared with the standard H3R antagonist PIT with an H3R affinity of $12 \mathrm{nM}$ (Table 1). Selected test compounds with the most promising in vivo anticonvulsant effects, namely 4 ( $1273.0 \mathrm{nM}$ for H1R, $69.3 \mathrm{nM}$ for H3R, >10,000 nM for H4R), 7 (915 nM for H1R, $40.5 \mathrm{nM}$ for H3R, >10,000 nM for H4R), and 13 (1338.0 nM for H1R, $137.2 \mathrm{nM}$ for H3R, >10,000 nM for H4R), showed a selectivity profile toward H3Rs with at least 10-fold lower affinity at hH1- and H4Rs.

\subsubsection{In Vivo Seizure Models}

With regard to the MES test, the current one used in the study produced seizures in $100 \%$ of animals without mortality. Likewise, the dose of PTZ and STR used in the present study formed seizures (score $4-5$ ) in 100\% of animals without mortality.

\section{Anticonvulsant Screening of H3R Antagonists 1-16 in MES-Induced Seizure}

The preliminary screening for anticonvulsant activities of acute systemic pretreatment with H3R ligands 1-16 on MES-induced seizures in rats was carried out and the observed results were compared with the protective effect of the reference antiepileptic drug PHT in MES-induced seizure in rats (Tables 2 and 3). The obtained results showed that acute systemic administration of PHT $(10 \mathrm{mg} / \mathrm{kg}$, i.p.) and H3R ligands 1-16 (10 mg/kg, i.p.) demonstrated a significant protection against MES-induced seizures as confirmed by one-way analysis of variance $\left[F_{(17,108)}=8.352 ; p<0.001\right]$. Among the H3R antagonists tested and following post hoc analyses, compound 4 at a dose of $10 \mathrm{mg} / \mathrm{kg}$ significantly exhibited the most promising protective effect in MES-induced seizure when compared with the saline-treated group with $\left[F_{(1,12)}=34.608 ; p<0.001\right]$, and provided comparable protection to that of PHT with $\left[F_{(1,12)}=1.135 ; p<0.308\right]$ (Tables 2 and 3, Figure 1). Moreover, the protection observed 
with H3R antagonist 4 at a dose of $10 \mathrm{mg} / \mathrm{kg}$, i.p. was significantly higher than that found for H3R antagonists 3, 5, 6, 7, 8, and 14 with $\left[F_{(1,12)}=5.882 ; p<0.05\right],\left[F_{(1,12)}=9.722 ; p<0.05\right],\left[F_{(1,12)}\right.$ $=8.20 ; p<0.05],\left[F_{(1,12)}=6.030 ; p<0.05\right],\left[F_{(1,12)}=11.377 ; p<0.05\right]$, and $\left[F_{(1,12)}=7.108 ; p<0.05\right]$, respectively (Table S1, Supplementary Material). On the other hand, the results show that animals pretreated with $2.5,5$, and $15 \mathrm{mg} / \mathrm{kg}$ of H3R antagonist 4 were protected to a significantly lesser extent against seizures when compared with the H3R antagonist $4(10 \mathrm{mg})$-treated group with $\left[F_{(1,11)}=6.087\right.$; $p<0.05]\left[F_{(1,11)}=21.843 ; p<0.001\right]$, and $\left[F_{(1,11)}=8.609 ; p<0.05\right]$, respectively (Figure 1). Moreover, the abrogation of H3R antagonist 4-provided protection was assessed by systemic co-administration with CNS penetrant histamine H3R agonist RAMH $(10 \mathrm{mg} / \mathrm{kg}$, i.p.). The results showed that co-injection with CNS penetrant histamine H3R agonist RAMH $(10 \mathrm{mg} / \mathrm{kg}$, i.p.) abrogated the H3R antagonist 4 (10 mg)-provided protection with $\left[F_{(1,10)}=0.711 ; p=0.419\right]$ for the comparison of saline-saline vs. $4+$ RAMH (Figure 2). Notably, RAMH when administered alone did not affect MES-induced seizures with $\left[F_{(1,10)}=0.359 ; p=0.563\right]$ for saline-saline vs. saline-RAMH (Figure 1).

Anticonvulsant Screening for H3R Antagonists 1-16 in PTZ-Induced Seizures

The protective effects of H3R antagonists 1-16 (10 mg/kg, i.p.) were assessed and compared with the protection obtained for the reference antiepileptic drug VPA in PTZ-induced seizures in rats (Tables 2 and 3). The results show that acute systemic pretreatment with VPA ( $300 \mathrm{mg} / \mathrm{kg}$, i.p.) and H3R antagonists 1-16 delivered a significant protective action against PTZ-induced seizures as confirmed by applying one-way analysis of variance $\left[F_{(17,108)}=23.925 ; p<0.001\right]$ (Tables 2 and 3 ). Pairwise comparison of the provided protective effects observed over 30 min revealed that H3R antagonists 4, 7, and $\mathbf{1 1}$ delivered full protective activities when compared with the saline-treated group (all $p<0.001)$ (Tables 2 and 3). Similarly, VPA (300 mg/kg, i.p.) provided full protection when compared with saline-treated group with $\left[F_{(1,12)}=653.40 ; p<0.001\right]$ (Tables 2 and 3 ). Moreover, analysis of variance revealed that full protection was provided after acute systemic administration with 10 or $15 \mathrm{mg} / \mathrm{kg}$ of H3R antagonist 4 (all $p<0.001$ ) (Figure 2, Tables 2 and 3). However, pretreatment with 2.5 or $5 \mathrm{mg} / \mathrm{kg}$ of H3R antagonist 4 provided significantly lower protection when compared with that provided with 10 or $15 \mathrm{mg} / \mathrm{kg}$ of the same compound (all $p<0.05$ ) (Figure 2, Tables 2 and 3). Furthermore, Figure 2 shows the reversal of H3R antagonist 4-provided protection when co-injected with $10 \mathrm{mg} / \mathrm{kg}$ of histamine H3R agonist RAMH. The observed results showed that RAMH failed to reverse the H3R antagonist 4-provided protection in PTZ-induced seizure model with $\left[F_{(1,12)}=2.40\right.$; $p=0.147$ ] for 6-treated group versus $4+$ RAMH-treated group (Figure 2). Importantly, RAMH alone did not affect seizure score when compared with effects of the saline-treated group with $p=0.232$ (Figure 2, Tables 2 and 3 ). 
Table 3. Effects of H3R antagonists 4 and $\mathbf{1 3}$ on THLE duration, average score, and percentage of provided protection against generalized tonic-clonic seizure (GTCS) in MES-, PTZ-, and STR-induced convulsion models.

\begin{tabular}{|c|c|c|c|c|c|c|c|}
\hline \multirow{2}{*}{ Group } & \multirow{2}{*}{$\begin{array}{c}\text { MES }^{\text {a }} \text {-Induced Seizure } \\
\text { Average THLE (s) }\end{array}$} & \multirow{2}{*}{ Group } & \multicolumn{2}{|c|}{ PTZ $^{\text {b}}$-Induced Seizure } & \multirow{2}{*}{ Group } & \multicolumn{2}{|c|}{ STR $^{\mathrm{c}}$-Induced Seizure } \\
\hline & & & Average Seizure Score & $\begin{array}{l}\text { \% Protection } \\
\text { against GTCS }\end{array}$ & & Average Seizure Score & $\begin{array}{c}\text { \% Protection } \\
\text { against GTCS }\end{array}$ \\
\hline SAL & $8.14 \pm 1.17$ & SAL & $4.71 \pm 0.16$ & 28.57 & SAL & 5 & 0 \\
\hline PHT (10 mg) & $0.90 \pm 0.19^{* *}$ & VPA (300 mg) & $0.00 \pm 0.00$ & 100 & VPA (300 mg) & 0 & 100 \\
\hline $4(2.5 \mathrm{mg})$ & $5.83 \pm 1.01 *$ & $4(2.5 \mathrm{mg})$ & $2.29 \pm 0.44^{*}$ & 100 & $4(2.5 \mathrm{mg})$ & - & - \\
\hline $4(5 \mathrm{mg})$ & $2.50 \pm 1.21^{* *, \#}$ & $4(5 \mathrm{mg})$ & $0.71 \pm 0.31^{* *, \#}$ & 100 & $4(5 \mathrm{mg})$ & - & - \\
\hline $4(10 \mathrm{mg})$ & $0.57 \pm 0.21 * * \$$ & $4(10 \mathrm{mg})$ & $0.00 \pm 0.00$ \& & 100 & $4(10 \mathrm{mg})$ & $4.57 \pm 0.19$ & 28.57 \\
\hline $4(15 \mathrm{mg})$ & $3.67 \pm 0.94^{* *, \#}$ & $4(15 \mathrm{mg})$ & $0.00 \pm 0.00 \&$ & 100 & $4(15 \mathrm{mg})$ & - & - \\
\hline $4(10 \mathrm{mg})+\mathrm{RAMH}$ & $6.17 \pm 0.59$ & $4(10 \mathrm{mg})+\mathrm{RAMH}$ & $0.29 \pm 0.16^{* *}$ & 100 & $4(10 \mathrm{mg})+\mathrm{RAMH}$ & - & - \\
\hline SAL + RAMH & $7.92 \pm 0.60$ & $\mathrm{SAL}+\mathrm{RAMH}$ & $4.29 \pm 0.25$ & 14.29 & $\mathrm{SAL}+\mathrm{RAMH}$ & - & - \\
\hline $13(2.5 \mathrm{mg})$ & - & $13(2.5 \mathrm{mg})$ & - & - & $13(2.5 \mathrm{mg})$ & $4.86 \pm 0.13$ & 14.29 \\
\hline $13(5 \mathrm{mg})$ & - & $13(5 \mathrm{mg})$ & - & - & $13(5 \mathrm{mg})$ & $3.00 \pm 0.31$ ** & 85.71 \\
\hline $13(10 \mathrm{mg})$ & $6.43 \pm 1.14$ & $13(10 \mathrm{mg})$ & $2.14 \pm 0.47^{*}$ & 85.71 & 13 (10 mg) & $2.00 \pm 0.35^{* *}$ & 100 \\
\hline $13(15 \mathrm{mg})$ & - & $13(15 \mathrm{mg})$ & - & - & $13(15 \mathrm{mg})$ & $2.17 \pm 0.31^{* *}$ & 100 \\
\hline 13 (10 mg) + RAMH & - & $13(10 \mathrm{mg})+\mathrm{RAMH}$ & - & - & $13(10 \mathrm{mg})+\mathrm{RAMH}$ & $2.14 \pm 0.35^{* *}$ & 100 \\
\hline $\mathrm{SAL}+\mathrm{RAMH}$ & - & $\mathrm{SAL}+\mathrm{RAMH}$ & - & - & SAL + RAMH & $4.71 \pm 0.16$ & 28.57 \\
\hline
\end{tabular}

a $50-\mathrm{Hz}$ alternating current of $120 \mathrm{~mA}$ intensity applied through ear electrodes for a duration of $1 \mathrm{~s},{ }^{\mathrm{b}} 60 \mathrm{mg} / \mathrm{kg},{ }^{\mathrm{c}} 3.5 \mathrm{mg} / \mathrm{kg}$. -: not determined. $+:$ means that two compounds were co-administered to the tested animals. ${ }^{*} p<0.05$ vs. (saline)-treated group. ${ }^{* *} p<0.001$ vs. (saline)-treated group. ${ }^{\#} p<0.05 \mathrm{vs} .(2.5 \mathrm{mg})$-treated group. ${ }^{\$} p<0.05 \mathrm{vs} .(5 \mathrm{mg}$ or $15 \mathrm{mg})$-treated groups. ${ }^{\&}$ Full protection. SAL—saline; PHT—phenytoin; VPA—valproic acid; RAHM- $(R)-\alpha$-methylhistamine. 
Anticonvulsant Screening for H3R Antagonists 1-16 in STR-Induced Seizures

In STR-induced seizure in rats, H3R antagonist 4 with the most promising effect in MES- and PTZ-induced seizures failed to provide any appreciable protection in STR-induced seizure when compared with the saline-treated group after $30 \mathrm{~min}$ of observation time with $\left[F_{(1,12)}=4.50 ; p=0.055\right]$ (Tables 2 and 3). However, H3R antagonist 13 without protection in MES-induced seizure and with weak protection in PTZ-induced seizure exhibited a moderate protective effect in STR-induced seizure when compared with the saline-treated group with $\left[F_{(1,12)}=63.00 ; p<0.001\right]$ (Figure 3, Table 3). Notably, the reference antiepileptic drug VPA (VPA $300 \mathrm{mg} / \mathrm{kg}$, i.p.) showed significant protection when compared with saline-treated group after 30 min observation time with $\left[F_{(1,12)}=236.308 ; p<0.001\right]$ (Figure 3, Tables 2 and 3). Moreover, the results showed that acute systemic pretreatment with H3R antagonist 13 at a lower dose $(2.5 \mathrm{mg} / \mathrm{kg}$, i.p.) failed to exhibit protection against STR-induced seizures when compared with the saline-treated group with $\left[F_{(1,12)}=1.00 ; p=0.337\right]$ (Figure 3, Tables 2 and 3). Furthermore, no significant differences in the protection provided by H3R antagonist $13(10 \mathrm{mg} / \mathrm{kg}$, i.p.) were observed when 5 or $15 \mathrm{mg} / \mathrm{kg}$ of the same compound was administered with $\left[F_{(1,12)}=2.842\right.$; $p=0.118]\left[F_{(1,12)}=0.079 ; p=0.784\right]$, respectively (Figure 3, Table 3).

\subsection{ADME-Tox Properties}

\subsubsection{Antiproliferative Assay}

The effect of H3R antagonist $4(0.1-100 \mu \mathrm{M})$ on proliferation of HEK-293 and hepatoma HepG2 cell lines was assessed and compared with the reference cytostatic drug doxorubicin (DX) and hepatotoxin carbonyl cyanide 3-chlorophenylhydrazone (CCCP) (Figure 4A,B). The results showed that H3R antagonist 4 significantly decreased proliferation of HepG2 cells only at the highest concentration used $(100 \mu \mathrm{M})$, however, decline in proliferation of HEK-293 cells was achieved with two doses of the same compound, namely 10 and $100 \mu \mathrm{M}(p<0.001)$ (Figure 4A,B).

A

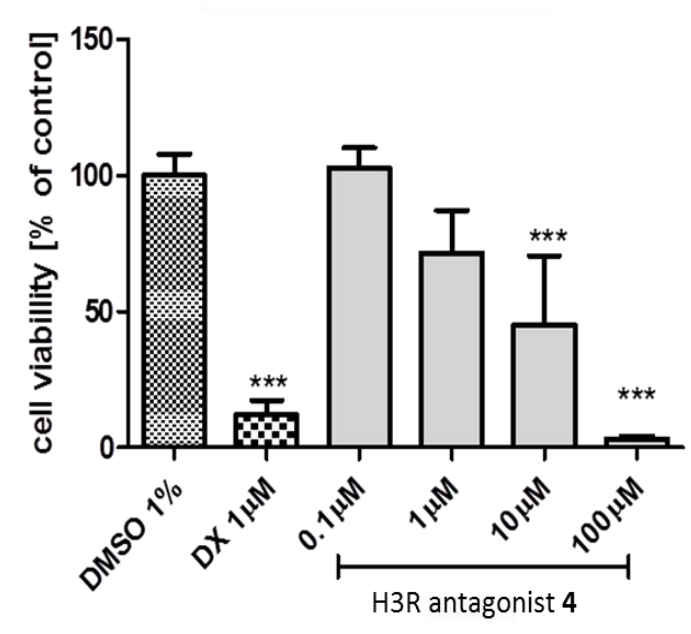

${ }^{\star \star \star}=p<0.001$

\section{B}

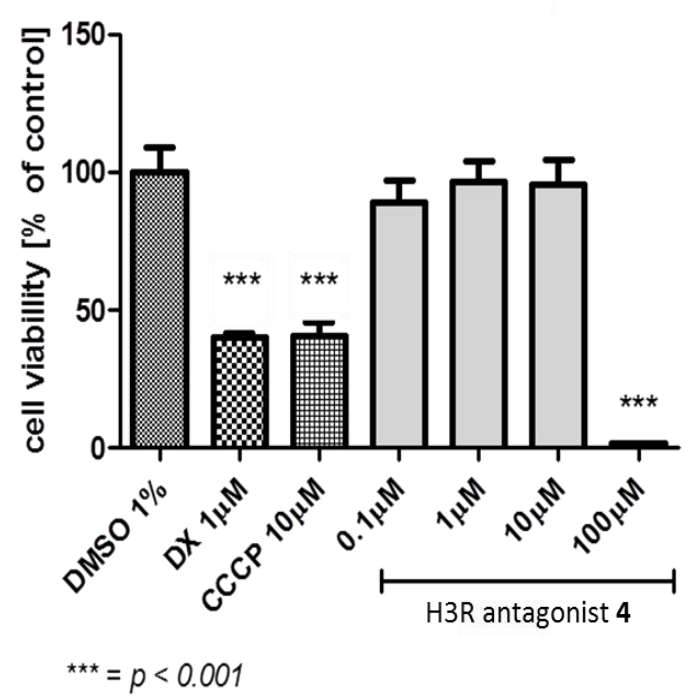

Figure 4. Antiproliferative effects of H3R antagonist 4. (A) Antiproliferative effects of the reference drug doxorubicin (DX) and H3R antagonist 4 on HEK-293 cell line after $72 \mathrm{~h}$ of incubation. (B) Antiproliferative effects of the reference drug doxorubicin (DX), hepatotoxin carbonyl cyanide 3-chlorophenylhydrazone (CCCP), and H3R antagonist 4 on HepG2 cell line after $72 \mathrm{~h}$ of incubation. DMSO: dimethyl sulfoxide. 


\subsubsection{In Silico Metabolic Stability}

The computational procedure MetaSite.5.1.1 provided by Molecular Discovery Ltd. indicated the sixth position of naphthalene moiety as the most probable site of H3R antagonist 4 metabolism (blue circle marked; Figure 5). Moreover, the azepane moiety was also shown to be susceptible for metabolic biotransformations (the darker red color of the marked functional group indicates its higher probability of being involved in the metabolism pathway; Figure 5). The predicted in silico most probable metabolic routes included hydroxylation at the sixth position of naphthalene or azepane group followed by the compound's oxidative degradation of the aliphatic alkyl chain (data not shown).

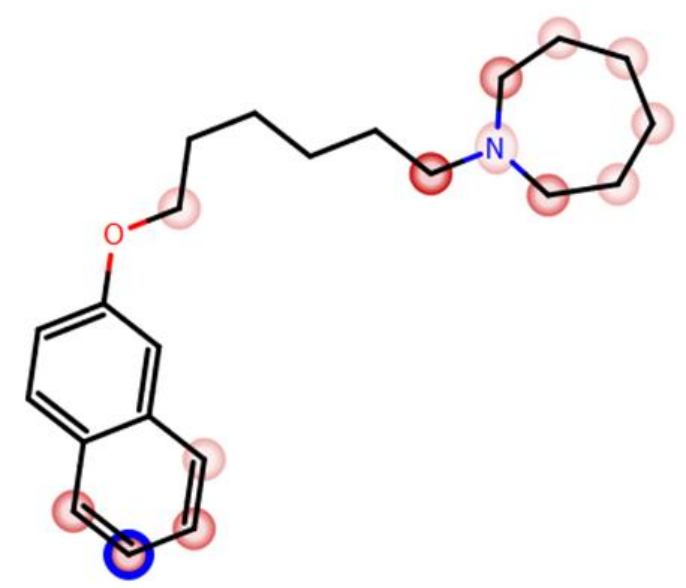

Figure 5. Potential sites of metabolism for H3R antagonist 4. The blue circle marks the site involved in metabolism with the highest probability. Other potential sites are marked with red color; the darker the color, the higher the probability of involvement in the metabolism pathway (calculated with MetaSite [53]).

\subsubsection{In Vitro Metabolic Stability}

The UPLC analysis of the reaction mixture of H3R antagonist 4 incubated for 120 min with rat liver microsomes (RLMs) showed that $\sim 18 \%$ of this compound was converted into four metabolites, namely M-I-M-IV (Figure 6A). The MS determination of the molecular mass of the main metabolite $\mathrm{M}-\mathrm{I}$ (+32 units) and the comparison of the ion fragments analyses of H3R antagonist 4 and metabolite M-I suggests the double-hydroxylation at the 6- $n$-hexylazepane moiety as the main metabolic pathway (Figure 6B). Moreover, the hydroxylation reactions at the naphthalene moiety and at the aliphatic alkyl chain were also identified (metabolites M-II-M-IV, Figure 6C). 
A

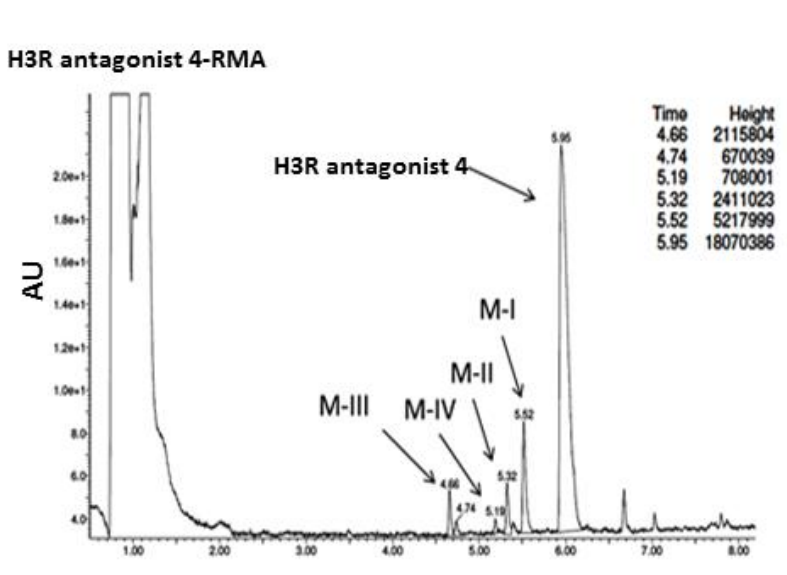

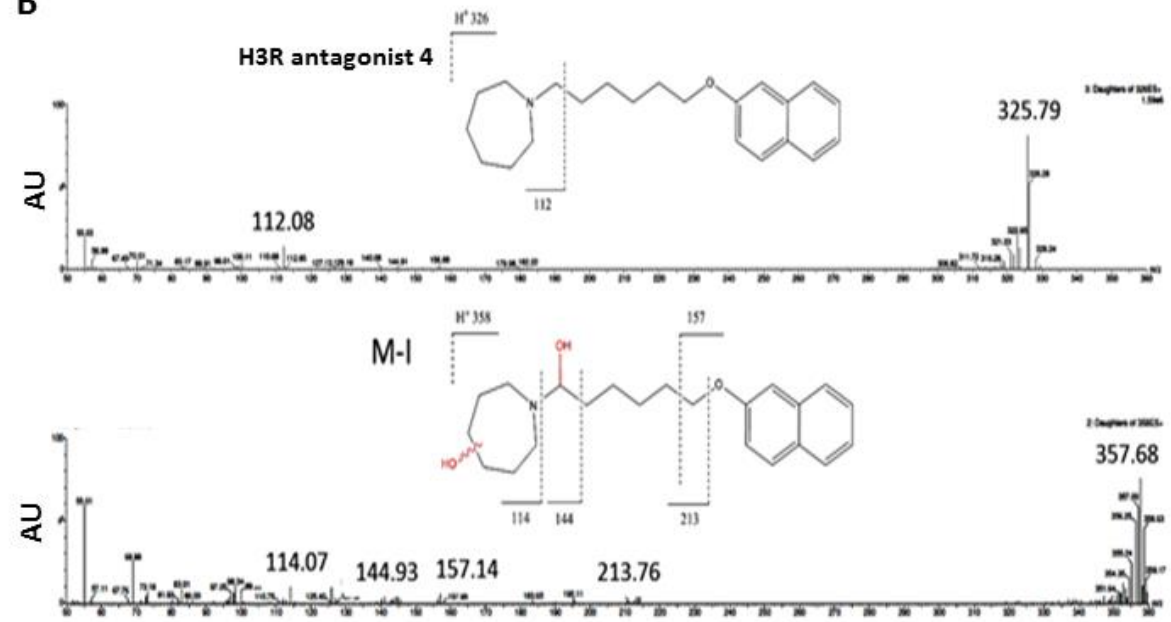

Figure 6. Cont 


\section{C}

H3R antagonist 4-RMA

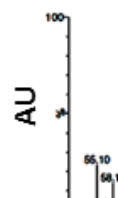

M-II

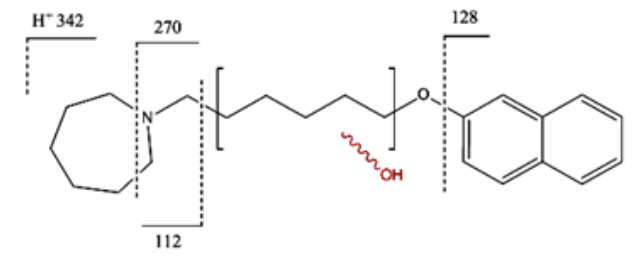

$\begin{array}{ll}112.07 & 128.17\end{array}$

270.33

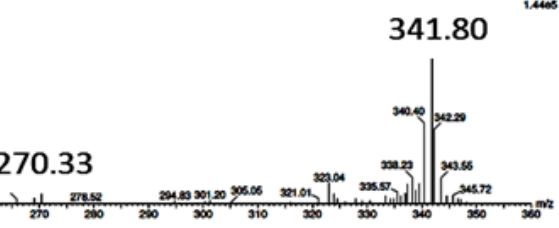

H3R antagonist 4-RMA

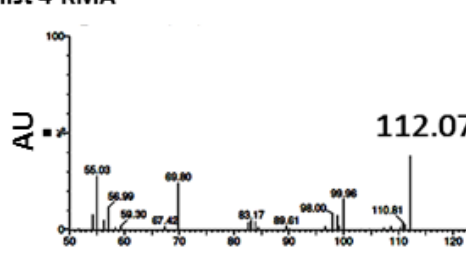

M-III

$\stackrel{\mathrm{H}^{+} 342}{\square}$

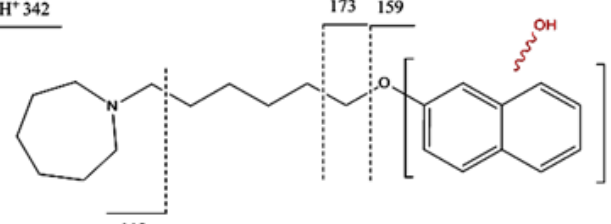

342.08

112

$159.74 \quad 173.04$

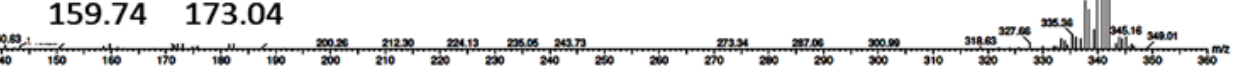

H3R antagonist 4-RMA

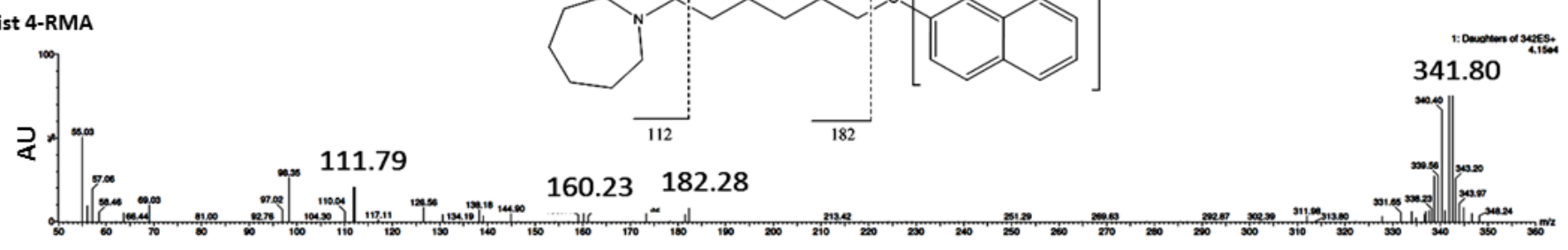

Figure 6. The metabolic profile of H3R antagonist after incubation of H3R antagonist 4 with rat liver microsomes. The UPLC spectrum obtained two hours post incubation of H3R antagonist 6 with rat liver microsomes. (A) Around 20\% of H3R antagonist 4 was metabolized. (B) Main metabolite MI of H3R antagonist 4 with a double-hydroxylation identified as the main metabolic route. (C) The mass spectrometry (MS) fragmentation analysis of most probable hydroxylation sites MII-MIV with rat liver microsomes. Abbreviations: UPLC, ultra-performance liquid chromatography. 


\subsubsection{Metabolic Interactions}

The results observed in luminescent CYP3A4 P450-Glo ${ }^{\mathrm{TM}}$ assay showed no inhibitory effects of H3R antagonist 4 on CYP3A4 activity at examined concentrations of $0.1-25 \mu \mathrm{M}$ (Figure 7A). Moreover, the observed results in luminescent CYP2D6 P450-Glo ${ }^{\mathrm{TM}}$ assay revealed that the inhibitory effect of $\mathrm{H} 3 \mathrm{R}$ antagonist 6 was detected with an $\mathrm{IC}_{50}$ value of $0.67 \mu \mathrm{M}$ (Figure 7B).
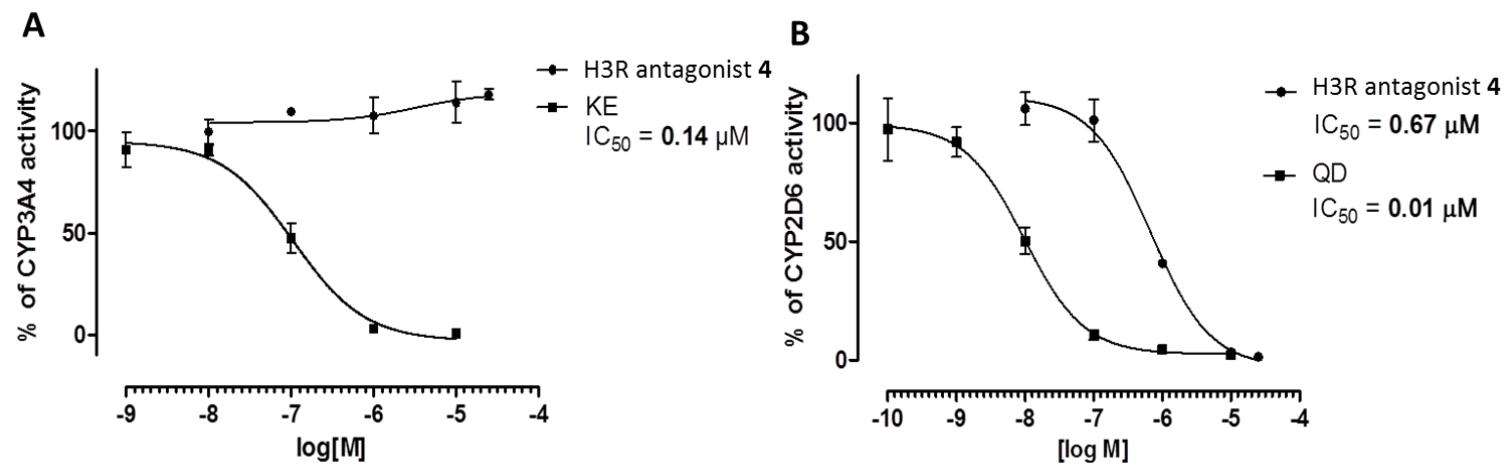

Figure 7. Effect of H3R antagonist 4 on CYP3A4 and CYP2D6 activity. (A) Effects of ketoconazole (KE) and H3R antagonist 4 on CYP3A4 activity. (B) Effect of quinidine (QD) and H3R antagonist 4 on CYP2D6 activity.

\section{Discussion}

\subsection{In Vitro Histamine H3 Receptor Affinity of Test Compounds 1-16}

All novel H3R antagonists were evaluated in the form of hydrogen oxalate salts in radioligand displacement assays. Tested H3R antagonists 1-16 displayed affinities at the human H3R in a nanomolar concentration range $\left(K_{\mathrm{i}}: 36-137 \mathrm{nM}\right.$, Table 1$)$. Compounds 13-15 displayed $K_{\mathrm{i}}$ values similar to that of pitolisant (12 nM, Table 1), while the 4-fluorophenyl derivatives were the least potent ones (11-13; $K_{\mathrm{i}}$ : 83.6-137.2 nM).

\subsection{Selectivity of Selected H3R Antagonists towards Other Histamine Receptors (H1 and H4)}

\subsubsection{Histamine $\mathrm{H} 1$ Receptor Affinity}

As the two histamine receptors H1R and H3R play a pivotal role in the anticonvulsant activity of the central histamine [41], selected H3R antagonists $(\mathbf{6}, \mathbf{9}$, and $\mathbf{1 5})$ were examined in a binding assay at the human histamine H1R and showed weak affinities $\left(915 \leq K_{\mathrm{i}} \leq 1338 \mathrm{nM}\right)$, being 10-fold lower than at the H3R.

\subsubsection{Histamine $\mathrm{H} 4$ Receptor Affinity}

As H3R represents the highest degree of homology with H4R [19], the potential interaction with this receptor subtype for selected H3R antagonists $(4,7$, and 13) was evaluated. The observed results showed that none of the tested H3R antagonists displayed affinity for hH4R $\left(K_{\mathrm{i}}>10,000 \mathrm{nM}\right)$.

\subsection{In Vivo Anticonvulsant Activity}

The results demonstrated that H3R antagonist 4 exhibited the most promising protection against MES-induced seizures when animals were administered with $10 \mathrm{mg} / \mathrm{kg}$ i.p., and as compared with the saline-treated group of animals (Tables 2 and 3). However, lower doses ( 2.5 and $5 \mathrm{mg} / \mathrm{kg}$, i.p.) and a higher dose (15 mg/ $\mathrm{kg}$, i.p.) failed to increase the $(10 \mathrm{mg}) \mathrm{H} 3 \mathrm{R}$ antagonist 4-provided protection (Figure 1, Table 3). Accordingly, the observed results show a dose-response relationship of the protection provided and the presence of a ceiling effect for H3R antagonist 4 in the MES-induced seizure model achieved with a dose of $10 \mathrm{mg} / \mathrm{kg}$, i.p. (Figure 1, Table 3). Notably, the protective 
effect of H3R antagonist $4(10 \mathrm{mg} / \mathrm{kg}$, i.p.) was similar to that observed in the group treated with the reference antiepileptic drug PHT (10 mg/ $\mathrm{kg}$, i.p.), and was significantly higher than that observed for H3R ligands 3, 5, 6, 7, 8, and 14 (Figure 1, Table 1). The latter observations are in agreement with recent preclinical outcomes that showed a dose-dependent anticonvulsant effect of several H3R antagonists tested in several animal models of seizures. Also, the present results are in line with earlier observations for the H3R antagonist PIT in a photosensitivity seizure model in adult patients, and in agreement with earlier observations for several H3R antagonists tested for their anticonvulsant potential in different animal models of seizures [25-30,33,40,54]. An additional test in the present study showed that the protection observed for H3R antagonist 4 was abolished when animals were co-administered with the CNS penetrant histamine H3R agonist RAMH (10 mg/kg i.p.) (Figure 1, Table 3), proposing that the provided protective effect of H3R antagonist 4 in the MES-induced seizure model involves, at least to some extent, H3R blockade provided by H3R antagonist 4. Notably, these observations are consistent with the earlier preclinical results for numerous imidazole- and non-imidazole-based H3R antagonists [14,25-30,40,54].

H3Rs are auto-receptors presynaptically positioned on histaminergic neurons with an inhibitory effect on the biosynthesis and release of histamine [21]. Therefore, blocking H3Rs by selective H3R antagonists, such as H3R antagonist 4, would escalate neuronal release of brain histamine, providing the protection in the MES-induced seizure in rats. The latter proposed mechanism underlying the anticonvulsant effect of H3R antagonist 4 is also in line with previous preclinical observations in animal seizure models in which high doses of several centrally acting H1R antagonists used as anti-allergic drugs promoted the development of convulsions of tested animals, indicating the involvement of H1R antagonism, and consequently, brain histaminergic neurotransmission in the seizure promotion. Noticeably, similar protective effects of imidazole-based and non-imidazole-based H3R antagonists were earlier described to be abolished either by H3R agonists or by centrally acting H1R antagonists, suggesting an interaction of the H3R antagonism-released histamine with postsynaptically located H1Rs on neurons [14,25-30,53,54].

In the PTZ-induced seizure mode, acute systemic administration of VPA $(100 \mathrm{mg} / \mathrm{kg}$, i.p.) as well as H3R antagonists 4, 7, and $\mathbf{1 1}(10 \mathrm{mg} / \mathrm{kg}$, i.p.) showed full protection (Figure 2, Table 3). Furthermore, the anticonvulsant effects observed for H3R antagonist 4 at lower doses ( 2.5 and $5 \mathrm{mg} / \mathrm{kg}$, i.p.) or a higher dose $(15 \mathrm{mg} / \mathrm{kg}$, i.p.) showed a dose-dependent protection in the PTZ-induced seizure model (Figure 2, Table 3). However, the protective effect of H3R antagonist $4(10 \mathrm{mg} / \mathrm{kg}$, i.p.) was not reversed when rats were pretreated with RAMH $(10 \mathrm{mg} / \mathrm{kg}$, i.p.) before PTZ challenge, suggesting that the protection observed for H3R antagonist 4 in PTZ-induced seizure is not facilitated through modulation of central histaminergic neurotransmission (Figure 2, Table 3). The latter observation may be explained with the differences in the triggers or the mechanisms and types of seizures each model represents (MES is considered as a model of generalized tonic-clonic seizures, whereas PTZ $(60 \mathrm{mg} / \mathrm{kg}$, i.p.) induces generalized myoclonic and/or tonic-clonic seizures) [11,53-55]. The failure of RAMH to reverse the protections provided by H3R antagonist 4 might be explained with its capability to reduce the suppression of glutamatergic and GABAergic synaptic transmission through blockade of $\mathrm{H} 3$ heteroreceptor function in CNS, necessitating additional future investigations of whether H3R antagonist 4 modulated the release of inhibitory neurotransmitters, for example, GABA [56].

In the STR-induced seizure model, the results showed that acute systemic administration of $\mathrm{H} 3 \mathrm{R}$ antagonists 4, 7, and $\mathbf{1 1}$ (10 mg/ $\mathrm{kg}$, i.p.) failed to exhibit appreciable protection during $30 \mathrm{~min}$ of the time observation, whereas H3R antagonist 13 with moderate protection in PTZ and without any considerable protection in MES demonstrated reasonable protection following $30 \mathrm{~min}$ during the time observation (Figure 3, Table 3). Moreover, the lower doses (2.5 and $5 \mathrm{mg} / \mathrm{kg}$, i.p.) as well as the higher dose (15 mg/ $\mathrm{kg}$, i.p.) of H3R antagonist 13 failed to exhibit a dose-dependent protection against STR-induced seizure in rats (Figure 3, Table 3). In resemblance to the observations in PTZ-induced seizure, an additional experiment showed that the H3R antagonist 13-provided moderate protection in STR-induced seizure was not reversed when animals were co-injected with 
$10 \mathrm{mg} / \mathrm{kg}$ i.p. of the CNS penetrant histamine H3R agonist RAMH 30-45 min before STR challenge (Figure 3, Table 3). These findings in STR-induced seizure further comprehend the present results for the protective effects of the H3R antagonist 4 in PTZ-induced seizure model, as both models are considered as chemically-induced seizure models. The latter observations for H3R antagonists 1-16 in the STR-induced seizure model show that the moderate protection provided with H3R antagonist 13 in STR model is also not facilitated through central histaminergic neurotransmission. Notably, STR is an established competitive antagonist of the inhibitory amino acid glycine. Therefore, the inability of H3R antagonist $\mathbf{1 3}$ to afford a dose-dependent protection against STR-induced seizure model advocates little or no modulation effect of H3R antagonist 13 on the glycine receptors, because the mechanisms underlying STR-induced seizures are supposed to be attributed to its blocking activity on glycine receptors in the brain as well as in the spinal cord [56]. Notably, most marketed AEDs were not effective in all conducted convulsion models during preclinical drug development. Accordingly, carbamazepine, oxcarbazepine and PHT were found to be, and are still, highly effective in MES-induced model in rodents, however, they failed to protect against convulsions in rodents induced by PTZ, STR, or picrotoxin $[57,58]$. On the contrary, ethosuximide and tiagabine, which show high protection in chemically-induced convulsion models in rodents, lack protection in the MES-induced model when used at nontoxic doses [58]. Nonetheless, the diversity in preclinical activities detected for numerous AEDs was translated into the clinical utility of PHT, carbamazepine, and oxcarbazepine, but not ethosuximide or tiagabine, in patients diagnosed with generalized tonic-clonic convulsions.

\subsection{ADME-Tox Properties}

The most promising H3R antagonist 4 was selected to evaluate its ADME-Tox properties, which included the determination of the in vitro safety profile by applying eukaryotic cell lines, the in silico and in vitro determination of the metabolic stability and main metabolic routes, and the in vitro assessment of potential drug-drug interactions by bioluminescent enzymatic assays.

In order to determine the potential toxicity, the standard colorimetrical MTS test was used. This test allowed one to follow up the influence of H3R antagonist 4 on the human embryonic kidney (HEK-293) and hepatoma HepG2 cell lines' proliferation. The antiproliferative activity of H3R antagonist 4 differed between both used cell lines. HEK-293 cells were more susceptible for antiproliferative activity as revealed in the statistically significant decrease of HEK-293 cell line viability $(p<0.001)$, which was observed at concentrations of 10 and $100 \mu \mathrm{M}$, whereas in the HepG2 cell line, the antiproliferative effect was achieved only at a concentration of $100 \mu \mathrm{M}$ (Figure 4A,B). However, the obtained results for HEK-293 indicated a satisfying safety profile of H3R antagonist 4 in comparison with the reference DX, which significantly decreased HEK-293 viability at a much lower concentration $(1 \mu \mathrm{M})$ (Figure 4A). Moreover, no significant hepatotoxic effect was observed for H3R antagonist 4, as the reference drug CCCP decreased HEpG2 viability at $10 \mu \mathrm{M}$, whereas H3R antagonist 4 only did so at $100 \mu \mathrm{M}$ (Figure $4 \mathrm{~B})$.

In further in vitro metabolic stability studies, the results observed for H3R antagonist 4 applying RLMs revealed good metabolic stability of H3R antagonist 4 , as only $\sim 18 \%$ of the substrate was metabolized and converted into four different metabolites after $120 \mathrm{~min}$ of incubation at $37^{\circ} \mathrm{C}$ (Figure 6). Moreover, the in silico data and the MS fragmentation analyses showed one hydroxylation on the azepane moiety and another hydroxylation on the hexyl chain, followed by oxidative degradation of the alkyl chain as the main metabolic routes of H3R antagonist 4 (Figure 5).

Furthermore, H3R antagonist 4 did not affect CYP3A4, whereas CYP2D6 was inhibited in a more pronounced manner. However, this effect was observed with a 67 -fold higher $\mathrm{IC}_{50}\left(\mathrm{IC}_{50}=0.67 \mu \mathrm{M}\right)$ as compared with the reference drug QD with a calculated $\mathrm{IC}_{50}$ value of $0.01 \mu \mathrm{M}$ (Figure 7).

\section{Conclusions}

The tested series of H3R antagonists showed in vitro affinity at the hH3R in the nanomolar range. The most promising H3R antagonist 4 having the 1-(6-(naphthalen-2-yloxy)hexyl)azepane 
pharmacophore exhibited an affinity for hH3R $\left(K_{\mathrm{i}}=69.3 \mathrm{nM}\right)$. The in vivo anticonvulsant results revealed that H3R antagonist 4 exhibited most promising protection following acute systemic administration in MES- and PTZ-induced seizure models in rats. Moreover, the protection observed for H3R antagonist 4 in the MES-induced seizure model was fully reversed when rats were pretreated with the CNS-penetrant H3R agonist RAMH. However, RAMH failed to abrogate the protective effects observed for H3R antagonist in PTZ- or STR-induced seizure models, indicating that histaminergic pathways appear to be involved in the provided anticonvulsant efficacy of H3R antagonist 4 in only the MES-induced seizure model, but additional pharmacological properties of the compounds or their metabolites cannot be fully excluded. Moreover, ADME-Tox parameters' screening revealed satisfying low cytotoxicity, good metabolic stability, as well as no inhibition of CYP3A4 activity and moderate inhibition of CYP2D6 activity. Therefore, the overall experimental observations provide promising potential for the novel H3R antagonist 4 to be used as a potential template for further drug design and synthesis in the search for potent and active in vivo H3R antagonists, for example, as AED drugs with a high safety profile. Nonetheless, a battery of additional seizure models with different species is still required to further corroborate the current results observed for H3R antagonist 4, and to strengthen the translational value of its potential applicability in the therapeutic management of epilepsy.

Supplementary Materials: Supplementary Materials can be found at http://www.mdpi.com/1422-0067/19/11/ 3386/s1.

Author Contributions: B.S. was responsible for the study concept, design, acquisition, and analysis of animal data. A.A. conducted in vivo seizure experiments. G.L., A.L., J.H., and E.H.-O. were responsible for determination of antiproliferative activity, evaluation of in silico and in vitro metabolic stability, and drug-drug interaction probability of the obtained compounds. A.S. was responsible for carrying out tests of novel ligands for human histamine $\mathrm{H} 1$ receptors. A.F. and H.S. were responsible for affinity evaluation of novel ligands at the human histamine H3 and H4 receptors. K.K.-K. and D.E. were responsible for the design, synthesis, and analysis of all novel H3R antagonists. BS drafted the manuscript. K.K.-K., D.Ł., A.F., and H.S. provided critical revision for the manuscript. All authors critically reviewed content and approved final version for publication.

Funding: Bassem Sadek was supported by intramural funds from the College of Medicine and Health Sciences and the Office of Graduate Studies and Research, UAE University. The authors acknowledge the partial support of National Science Center granted on the basis of decision number DEC-2016/23/B/NZ7/02327 (D.Ł.) and the Jagiellonian University grant K/ZDS/007121 (K.K.-K.). Support was kindly provided by the EU COST Action CA15135 (D.Ł., H.S. and K.K.-K.), as well by DFG INST 208/664-1 FUGG (H.S.).

Conflicts of Interest: The authors declare no conflict of interest.

\section{References}

1. Baulac, M.; de Boer, H.; Elger, C.; Glynn, M.; Kalviainen, R.; Little, A.; Mifsud, J.; Perucca, E.; Pitkanen, A.; Ryvlin, P. Epilepsy priorities in Europe: A report of the ILAE-IBE Epilepsy Advocacy Europe Task Force. Epilepsia 2015, 56, 1687-1695. [CrossRef] [PubMed]

2. Kobow, K.; Blumcke, I. Epigenetics in epilepsy. Neurosci. Lett. 2018, 667, 40-46. [CrossRef] [PubMed]

3. Lin, J.J.; Mula, M.; Hermann, B.P. Uncovering the neurobehavioural comorbidities of epilepsy over the lifespan. Lancet 2012, 380, 1180-1192. [CrossRef]

4. Schmidt, D. The clinical impact of new antiepileptic drugs after a decade of use in epilepsy. Epilepsy Res. 2002, 50, 21-32. [CrossRef]

5. Franco, V.; French, J.A.; Perucca, E. Challenges in the clinical development of new antiepileptic drugs. Pharmacol. Res. 2016, 103, 95-104. [CrossRef] [PubMed]

6. Burakgazi, E.; French, J.A. Treatment of epilepsy in adults. Epileptic Disord. 2016, 18, 228-239. [PubMed]

7. Di Giovanni, G.; Svob Strac, D.; Sole, M.; Unzeta, M.; Tipton, K.F.; Muck-Seler, D.; Bolea, I.; Della Corte, L.; Nikolac Perkovic, M.; Pivac, N.; et al. Monoaminergic and Histaminergic Strategies and Treatments in Brain Diseases. Front. Neurosci. 2016, 10, 541. [CrossRef] [PubMed]

8. Svob Strac, D.; Pivac, N.; Smolders, I.J.; Fogel, W.A.; De Deurwaerdere, P.; Di Giovanni, G. Monoaminergic Mechanisms in Epilepsy May Offer Innovative Therapeutic Opportunity for Monoaminergic Multi-Target Drugs. Front. Neurosci. 2016, 10, 492. [CrossRef] [PubMed] 
9. Kamei, C. Involvement of central histamine in amygdaloid kindled seizures in rats. Behav. Brain Res. 2001, 124, 243-250. [CrossRef]

10. Kamei, C.; Ishizawa, K.; Kakinoki, H.; Fukunaga, M. Histaminergic mechanisms in amygdaloid-kindled seizures in rats. Epilepsy Res. 1998, 30, 187-194. [CrossRef]

11. Vohora, D.; Pal, S.N.; Pillai, K.K. Histamine and selective H3-receptor ligands: A possible role in the mechanism and management of epilepsy. Pharmacol. Biochem. Behav. 2001, 68, 735-741. [CrossRef]

12. Miyata, I.; Saegusa, H.; Sakurai, M. Seizure-modifying potential of histamine H1 antagonists: A clinical observation. Pediatr. Int. 2011, 53, 706-708. [CrossRef] [PubMed]

13. Ago, J.; Ishikawa, T.; Matsumoto, N.; Ashequr Rahman, M.; Kamei, C. Mechanism of imipramine-induced seizures in amygdala-kindled rats. Epilepsy Res. 2006, 72, 1-9. [CrossRef] [PubMed]

14. Kakinoki, H.; Ishizawa, K.; Fukunaga, M.; Fujii, Y.; Kamei, C. The effects of histamine H3-receptor antagonists on amygdaloid kindled seizures in rats. Brain Res. Bull. 1998, 46, 461-465. [CrossRef]

15. Yawata, I.; Tanaka, K.; Nakagawa, Y.; Watanabe, Y.; Murashima, Y.L.; Nakano, K. Role of histaminergic neurons in development of epileptic seizures in EL mice. Brain Res. Mol. Brain Res. 2004, 132, 13-17. [CrossRef] [PubMed]

16. Onodera, K.; Yamatodani, A.; Watanabe, T. Effects of alpha-fluoromethylhistidine on locomotor activity, brain histamine and catecholamine contents in rats. Methods Find Exp. Clin. Pharmacol. 1992, 14, 97-105. [PubMed]

17. Tuomisto, L.; Tacke, U. Is histamine an anticonvulsive inhibitory transmitter? Neuropharmacology 1986, 25, 955-958. [CrossRef]

18. Zhang, L.S.; Chen, Z.; Huang, Y.W.; Hu, W.W.; Wei, E.Q.; Yanai, K. Effects of endogenous histamine on seizure development of pentylenetetrazole-induced kindling in rats. Pharmacology 2003, 69, 27-32. [CrossRef] [PubMed]

19. Panula, P.; Chazot, P.L.; Cowart, M.; Gutzmer, R.; Leurs, R.; Liu, W.L.; Stark, H.; Thurmond, R.L.; Haas, H.L. International Union of Basic and Clinical Pharmacology. XCVIII. Histamine Receptors. Pharmacol. Rev. 2015, 67, 601-655. [CrossRef] [PubMed]

20. Schneider, E.H.; Seifert, R. The histamine H-receptor and the central and peripheral nervous system: A critical analysis of the literature. Neuropharmacology 2015, 106, 116-128. [CrossRef] [PubMed]

21. Arrang, J.M.; Garbarg, M.; Schwartz, J.C. Auto-inhibition of brain histamine release mediated by a novel class (H3) of histamine receptor. Nature 1983, 302, 832-837. [CrossRef] [PubMed]

22. Arrang, J.M.; Garbarg, M.; Schwartz, J.C. Autoinhibition of histamine synthesis mediated by presynaptic H3-receptors. Neuroscience 1987, 23, 149-157. [CrossRef]

23. Brown, R.E.; Stevens, D.R.; Haas, H.L. The physiology of brain histamine. Prog. Neurobiol. 2001, 63, 637-672. [CrossRef]

24. Kuder, K.; Lazewska, D.; Latacz, G.; Schwed, J.S.; Karcz, T.; Stark, H.; Karolak-Wojciechowska, J.; Kiec-Kononowicz, K. Chlorophenoxy aminoalkyl derivatives as histamine H(3)R ligands and antiseizure agents. Bioorg. Med. Chem. 2016, 24, 53-72. [CrossRef] [PubMed]

25. Sadek, B.; Kuder, K.; Subramanian, D.; Shafiullah, M.; Stark, H.; Lazewska, D.; Adem, A.; Kiec-Kononowicz, K. Anticonvulsive effect of nonimidazole histamine H3 receptor antagonists. Behav. Pharmacol. 2014, 25, 245-252. [CrossRef] [PubMed]

26. Sadek, B.; Saad, A.; Latacz, G.; Kuder, K.; Olejarz, A.; Karcz, T.; Stark, H.; Kiec-Kononowicz, K. Non-imidazole-based histamine $\mathrm{H} 3$ receptor antagonists with anticonvulsant activity in different seizure models in male adult rats. Drug Des. Dev. Ther. 2016, 10, 3879-3898. [CrossRef] [PubMed]

27. Sadek, B.; Saad, A.; Schwed, J.S.; Weizel, L.; Walter, M.; Stark, H. Anticonvulsant effects of isomeric nonimidazole histamine H3 receptor antagonists. Drug Des. Dev. Ther. 2016, 10, 3633-3651. [CrossRef] [PubMed]

28. Sadek, B.; Saad, A.; Subramanian, D.; Shafiullah, M.; Lazewska, D.; Kiec-Kononowiczc, K. Anticonvulsant and procognitive properties of the non-imidazole histamine $\mathrm{H} 3$ receptor antagonist DL77 in male adult rats. Neuropharmacology 2016, 106, 46-55. [CrossRef] [PubMed]

29. Sadek, B.; Schwed, J.S.; Subramanian, D.; Weizel, L.; Walter, M.; Adem, A.; Stark, H. Non-imidazole histamine H3 receptor ligands incorporating antiepileptic moieties. Eur. J. Med. Chem. 2014, 77, 269-279. [CrossRef] [PubMed] 
30. Sadek, B.; Shehab, S.; Wiecek, M.; Subramanian, D.; Shafiullah, M.; Kiec-Kononowicz, K.; Adem, A. Anticonvulsant properties of histamine $\mathrm{H} 3$ receptor ligands belonging to $\mathrm{N}$-substituted carbamates of imidazopropanol. Bioorg. Med. Chem. Lett. 2013, 23, 4886-4891. [CrossRef] [PubMed]

31. Zhang, L.; Chen, Z.; Ren, K.; Leurs, R.; Chen, J.; Zhang, W.; Ye, B.; Wei, E.; Timmerman, H. Effects of clobenpropit on pentylenetetrazole-kindled seizures in rats. Eur. J. Pharmacol. 2003, 482, 169-175. [CrossRef] [PubMed]

32. Zhang, L.S.; Chen, J.F.; Chen, G.F.; Hu, X.Y.; Ding, M.P. Effects of thioperamide on seizure development and memory impairment induced by pentylenetetrazole-kindling epilepsy in rats. Chin. Med. J. 2013, 126, 95-100. [PubMed]

33. Kasteleijn-Nolst Trenite, D.; Parain, D.; Genton, P.; Masnou, P.; Schwartz, J.C.; Hirsch, E. Efficacy of the histamine 3 receptor (H3R) antagonist pitolisant (formerly known as tiprolisant; BF2.649) in epilepsy: Dose-dependent effects in the human photosensitivity model. Epilepsy Behav. 2013, 28, 66-70. [CrossRef] [PubMed]

34. Collart Dutilleul, P.; Ryvlin, P.; Kahane, P.; Vercueil, L.; Semah, F.; Biraben, A.; Schwartz, J.C.; De Seze, J.; Hirsch, E.; Collongues, N. Exploratory Phase II Trial to Evaluate the Safety and the Antiepileptic Effect of Pitolisant (BF2.649) in Refractory Partial Seizures, Given as Adjunctive Treatment During 3 Months. Clin. Neuropharmacol. 2016, 39, 188-193. [CrossRef] [PubMed]

35. Arrang, J.M.; Garbarg, M.; Lancelot, J.C.; Lecomte, J.M.; Pollard, H.; Robba, M.; Schunack, W.; Schwartz, J.C. Highly potent and selective ligands for histamine H3-receptors. Nature 1987, 327, 117-123. [CrossRef] [PubMed]

36. Ligneau, X.; Morisset, S.; Tardivel-Lacombe, J.; Gbahou, F.; Ganellin, C.R.; Stark, H.; Schunack, W.; Schwartz, J.C.; Arrang, J.M. Distinct pharmacology of rat and human histamine H(3) receptors: Role of two amino acids in the third transmembrane domain. Br. J. Pharmacol. 2000, 131, 1247-1250. [CrossRef] [PubMed]

37. Kollb-Sielecka, M.; Demolis, P.; Emmerich, J.; Markey, G.; Salmonson, T.; Haas, M. The European Medicines Agency review of pitolisant for treatment of narcolepsy: Summary of the scientific assessment by the Committee for Medicinal Products for Human Use. Sleep Med. 2017, 33, 125-129. [CrossRef] [PubMed]

38. Ligneau, X.; Perrin, D.; Landais, L.; Camelin, J.C.; Calmels, T.P.; Berrebi-Bertrand, I.; Lecomte, J.M.; Parmentier, R.; Anaclet, C.; Lin, J.S.; et al. BF2.649 [1-\{3-[3-(4-Chlorophenyl)propoxy]propyl\}piperidine, hydrochloride], a nonimidazole inverse agonist/antagonist at the human histamine H3 receptor: Preclinical pharmacology. J. Pharmacol. Exp. Ther. 2007, 320, 365-375. [CrossRef] [PubMed]

39. Sadek, B.; Stark, H. Cherry-picked ligands at histamine receptor subtypes. Neuropharmacology 2015, 106, 56-73. [CrossRef] [PubMed]

40. Sadek, B.; Saad, A.; Sadeq, A.; Jalal, F.; Stark, H. Histamine H3 receptor as a potential target for cognitive symptoms in neuropsychiatric diseases. Behav. Brain Res. 2016, 312, 415-430. [CrossRef] [PubMed]

41. Bhowmik, M.; Khanam, R.; Vohora, D. Histamine H3 receptor antagonists in relation to epilepsy and neurodegeneration: A systemic consideration of recent progress and perspectives. Br. J. Pharmacol. 2012, 167, 1398-1414. [CrossRef] [PubMed]

42. Sander, K.; Kottke, T.; Weizel, L.; Stark, H. Kojic acid derivatives as histamine H(3) receptor ligands. Chem. Pharm. Bull. 2010, 58, 1353-1361. [CrossRef] [PubMed]

43. Sadek, B.; Schreeb, A.; Schwed, J.S.; Weizel, L.; Stark, H. Drug-likeness approach of 2-aminopyrimidines as histamine H3 receptor ligands. Drug Des. Dev. Ther. 2014, 8, 1499-1513. [CrossRef] [PubMed]

44. Cheng, Y.; Prusoff, W.H. Relationship between the inhibition constant (K1) and the concentration of inhibitor which causes 50 per cent inhibition (I50) of an enzymatic reaction. Biochem. Pharmacol. 1973, 22, 3099-3108. [PubMed]

45. Lazewska, D.; Kaleta, M.; Hagenow, S.; Mogilski, S.; Latacz, G.; Karcz, T.; Lubelska, A.; Honkisz, E.; Handzlik, J.; Reiner, D.; et al. Novel naphthyloxy derivatives-Potent histamine H3 receptor ligands. Synthesis and pharmacological evaluation. Bioorg. Med. Chem. 2018, 26, 2573-2585. [CrossRef] [PubMed]

46. Alachkar, A.; Latacz, G.; Siwek, A.; Lubelska, A.; Honkisz, E.; Grybos, A.; Lazewska, D.; Handzlik, J.; Stark, H.; Kiec-Kononowicz, K.; et al. Anticonvulsant evaluation of novel non-imidazole histamine H3R antagonists in different convulsion models in rats. Pharmacol. Biochem. Behav. 2018, 170, 14-24. [CrossRef] [PubMed] 
47. Sadek, B.; Khanian, S.S.; Ashoor, A.; Prytkova, T.; Ghattas, M.A.; Atatreh, N.; Nurulain, S.M.; Yang, K.H.; Howarth, F.C.; Oz, M. Effects of antihistamines on the function of human alpha7-nicotinic acetylcholine receptors. Eur. J. Pharmacol. 2014, 746, 308-316. [CrossRef] [PubMed]

48. Loscher, W. Critical review of current animal models of seizures and epilepsy used in the discovery and development of new antiepileptic drugs. Seizure 2011, 20, 359-368. [CrossRef] [PubMed]

49. Serdiuk, S.E.; Gmiro, V.E. Phenylephrine potentiates antidepressive and eliminates sedative action of amitriptyline in rats. Ross Fiziol. Zh Im I M Sechenova 2014, 100, 18-26. [PubMed]

50. Racine, R.J. Modification of seizure activity by electrical stimulation. II. Motor seizure. Electroencephalogr. Clin. Neurophysiol. 1972, 32, 281-294. [CrossRef]

51. Sadek, B.; Oz, M.; Nurulain, S.M.; Jayaprakash, P.; Latacz, G.; Kiec-Kononowicz, K.; Szymanska, E. Phenylalanine derivatives with modulating effects on human alpha1-glycine receptors and anticonvulsant activity in strychnine-induced seizure model in male adult rats. Epilepsy Res. 2017, 138, 124-131. [CrossRef] [PubMed]

52. Cruciani, G.; Carosati, E.; De Boeck, B.; Ethirajulu, K.; Mackie, C.; Howe, T.; Vianello, R. MetaSite: Understanding metabolism in human cytochromes from the perspective of the chemist. J. Med. Chem. 2005, 48, 6970-6979. [CrossRef] [PubMed]

53. Loscher, W.; Honack, D.; Fassbender, C.P.; Nolting, B. The role of technical, biological and pharmacological factors in the laboratory evaluation of anticonvulsant drugs. III. Pentylenetetrazole seizure models. Epilepsy Res. 1991, 8, 171-189. [CrossRef]

54. Vohora, D.; Pal, S.N.; Pillai, K.K. Thioperamide, a selective histamine H3 receptor antagonist, protects against PTZ-induced seizures in mice. Life Sci. 2000, 66, PL297-PL301. [CrossRef]

55. Sowemimo, A.A.; Adio, O.; Fageyinbo, S. Anticonvulsant activity of the methanolic extract of Justicia extensa T. Anders. J. Ethnopharmacol. 2011, 138, 697-699. [CrossRef] [PubMed]

56. Takei, H.; Yamamoto, K.; Bae, Y.C.; Shirakawa, T.; Kobayashi, M. Histamine H3 Heteroreceptors Suppress Glutamatergic and GABAergic Synaptic Transmission in the Rat Insular Cortex. Front Neural Circuits. 2017, 9, 85. [CrossRef] [PubMed]

57. Swinyard, E.A.; Sofia, R.D.; Kupferberg, H.J. Comparative anticonvulsant activity and neurotoxicity of felbamate and four prototype antiepileptic drugs in mice and rats. Epilepsia 1986, 27, 27-34. [CrossRef] [PubMed]

58. White, H.S. Comparative anticonvulsant and mechanistic profile of the established and newer antiepileptic drugs. Epilepsia 1999, 40, S2-S10. [CrossRef] [PubMed] 